\title{
Correction to: Long-Term (over 10 Years) Retrospective Follow-up of Laparoscopic Adjustable Gastric Banding
}

Dvir Froylich $^{1,2} \cdot$ Tamar Abramovich-Segal $^{1} \cdot$ Guy Pascal $^{1} \cdot$ Ivy Haskins $^{3} \cdot$ Boaz Appel $^{1} \cdot$ Naama Kafri $^{1} \cdot$ David Hazzan $^{1}$

Published online: 1 December 2017

(C) Springer Science+Business Media, LLC, part of Springer Nature 2017

\section{Correction to: OBES SURG}

DOI 10.1007/s11695-017-2952-7

In the original article the spelling of author Naama Kafri was incorrect. It is correct here.

The online version of the original article can be found at DOI:10.1007/ s11695-017-2952-7.

Dvir Froylich

dvirfr7@gmail.com

1 The Lady Davis Institute, Carmel Medical Center, Haifa, Israel

2 Surgery B, The Lady Davis, Carmel Medical Center, 7 Michal Street, 3436212 Haifa, Israel

3 Cleveland Clinic, Comprehensive Hernia Center, Digestive Disease and Surgery Institute, Cleveland, OH, USA 